\title{
Chondroitinase and Antidepressants Promote Plasticity by Releasing TRKB from Dephosphorylating Control of PTP $\sigma$ in Parvalbumin Neurons
}

\author{
${ }^{\circledR}$ Angelina Lesnikova, ${ }^{\circledR}$ Plinio Cabrera Casarotto, ${ }^{\circledR}$ Senem Merve Fred, ${ }^{\circledR}$ Mikko Voipio, ${ }^{\circledR}$ Frederike Winkel, \\ ${ }^{\circledR}$ Anna Steinzeig, ${ }^{\circledR}$ Hanna Antila, ${ }^{\circledR}$ Juzoh Umemori, ${ }^{\circledR}$ Caroline Biojone, and ${ }^{\circledR}$ Eero Castrén \\ Neuroscience Center, HiLIFE, University of Helsinki, Helsinki 00290, Finland
}

Perineuronal nets (PNNs) are an extracellular matrix structure rich in chondroitin sulfate proteoglycans (CSPGs), which preferentially encase parvalbumin-containing $\left(\mathrm{PV}^{+}\right)$interneurons. PNNs restrict cortical network plasticity but the molecular mechanisms involved are unclear. We found that reactivation of ocular dominance plasticity in the adult visual cortex induced by chondroitinase $A B C$ (chABC)-mediated PNN removal requires intact signaling by the neurotrophin receptor TRKB in $\mathrm{PV}^{+}$neurons. Additionally, we demonstrate that chABC increases TRKB phosphorylation (pTRKB), while PNN component aggrecan attenuates brain-derived neurotrophic factor (BDNF)-induced pTRKB in cortical neurons in culture. We further found that protein tyrosine phosphatase $\sigma$ (PTP $\sigma$, PTPRS), receptor for CSPGs, interacts with TRKB and restricts TRKB phosphorylation. PTP $\sigma$ deletion increases phosphorylation of TRKB in vitro and in vivo in male and female mice, and juvenile-like plasticity is retained in the visual cortex of adult PTP $\sigma$-deficient mice $\left(\mathrm{PTP}^{+/-}\right)$. The antidepressant drug fluoxetine, which is known to promote TRKB phosphorylation and reopen critical periodlike plasticity in the adult brain, disrupts the interaction between TRKB and PTP $\sigma$ by binding to the transmembrane domain of TRKB. We propose that both chABC and fluoxetine reopen critical period-like plasticity in the adult visual cortex by promoting TRKB signaling in $\mathrm{PV}^{+}$neurons through inhibition of TRKB dephosphorylation by the PTP $\sigma$-CSPG complex.

Key words: BDNF; chABC; CSPG; perineuronal nets; PTPRS; RPTP $\sigma$

\section{Significance Statement}

Critical period-like plasticity can be reactivated in the adult visual cortex through disruption of perineuronal nets (PNNs) by chondroitinase treatment, or by chronic antidepressant treatment. We now show that the effects of both chondroitinase and fluoxetine are mediated by the neurotrophin receptor TRKB in parvalbumin-containing $\left(\mathrm{PV}^{+}\right)$interneurons. We found that chondroitinase-induced visual cortical plasticity is dependent on TRKB in $\mathrm{PV}^{+}$neurons. Protein tyrosine phosphatase $\sigma$ (PTP $\sigma$, PTPRS), a receptor for PNNs, interacts with TRKB and inhibits its phosphorylation, and chondroitinase treatment or deletion of PTP $\sigma$ increases TRKB phosphorylation. Antidepressant fluoxetine disrupts the interaction between TRKB and $\operatorname{PTP} \sigma$, thereby increasing TRKB phosphorylation. Thus, juvenile-like plasticity induced by both chondroitinase and antidepressant treatment is mediated by TRKB activation in $\mathrm{PV}^{+}$interneurons.

Received Aug. 25, 2020; revised Nov. 19, 2020; accepted Nov. 24, 2020.

Author contributions: C.B. and E.C. designed research; A.L., P.C.C., S.M.F., M.V., F.W., A.S., H.A., J.U., and C. B. performed research; J.U. contributed unpublished reagents/analytic tools; A.L. and C.B. analyzed data; A.L., C.B., and E.C. wrote the paper.

This work was supported by the Centre for International Mobility (CIMO) Grant TM-17-10472 (to A.L.), the ERC Grant \#322742-iPLASTICITY, EU Joint Program — Neurodegenerative Disease Research (JPND) CircProt Projects \#301225 and \#643417, Doctoral Program Brain \& Mind, Sigrid Jusélius Foundation, Jane and Aatos Erkko Foundation, and the Academy of Finland Grants \#294710 and \#307416 (to E.C.). We thank Sulo Kolehmainen and Seija Lågas for technical help, Dr. Heikki Rauvala for the donation of the PTP $\sigma$ knockout mice and for his expert comments on the manuscript, and Katja Kaurinkoski for language revision.

The authors declare no competing financial interests.

Correspondence should be addressed to Caroline Biojone at caroline.biojone@helsinki.fi or Eero Castrén at eero.castren@helsinki.fi.

https://doi.org/10.1523/JNEUROSCI.2228-20.2020

Copyright $\odot 2021$ Lesnikova et al.

This is an open-access article distributed under the terms of the Creative Commons Attribution 4.0 International license, which permits unrestricted use, distribution and reproduction in any medium provided that the original work is properly attributed.

\section{Introduction}

Plasticity is the ability of the brain to change itself through establishing new neuronal connections and rewiring existing ones. Plasticity is prominent in early life and it peaks during so-called "critical periods" when the ability of the brain to adapt is at its highest (Wiesel, 1982). After the end of the critical period, plasticity persists but at significantly diminished levels (Hübener and Bonhoeffer, 2014).

Closure of the critical periods is mediated by changes in cortical excitatory/inhibitory (E/I) balance that take place because of maturation of cortical inhibitory interneurons. Fast-spiking interneurons expressing parvalbumin $\left(\mathrm{PV}^{+}\right)$orchestrate synchronous neuronal oscillations and play a particularly important role in this process (Hensch, 2005). Closure of the critical period 
coincides with the functional maturation of $\mathrm{PV}^{+}$cells and establishment of perineuronal nets (PNNs) around them (Wang and Fawcett, 2012; Umemori et al., 2018; Fawcett et al., 2019). PNNs are mesh-like structures of extracellular matrix that surround the somata and proximal dendrites of $\mathrm{PV}^{+}$interneurons in particular (Kwok et al., 2011). Chondroitin sulfate proteoglycans (CSPGs), such as aggrecan and brevican, are major components of PNNs.

After the closure of a critical period, neuronal plasticity can still be modulated, and critical period-like plasticity can be induced in the adult brain by a number of different methods (Bavelier et al., 2010; Sale et al., 2014). Digestion of PNNs by chondroitinase $\mathrm{ABC}$ (chABC) treatment has been demonstrated to induce ocular dominance plasticity in the adult visual cortex (Pizzorusso et al., 2002). Local chondroitinase injections into different brain areas have also been shown to promote recovery of spinal cord injury (Bradbury et al., 2002) and extinction of fear memories in adult rodents (Gogolla et al., 2009; Hylin et al., 2013; Shi et al., 2019). However, the mechanisms through which chABC influences plasticity in the CNS remain unclear.

Antidepressant drugs also induce critical period-like plasticity in the adult brain (Castreń, 2013). Antidepressants activate neurotrophic receptor tyrosine kinase 2 (TRKB), the receptor for brain-derived neurotrophic factor (BDNF), and promote plasticity through its signaling pathways (Saarelainen et al., 2003; Duman and Monteggia, 2006; Castrén and Antila, 2017; Umemori et al., 2018). Like ChABC, fluoxetine, a widely prescribed antidepressant, induces ocular dominance plasticity in the rodent visual cortex (Maya Vetencourt et al., 2008) and makes fear-related memories in mice susceptible to erasure (Karpova et al., 2011). We have recently found that the activation of TRKB in $\mathrm{PV}^{+}$interneurons is both necessary and sufficient for antidepressant-induced plasticity in the mature CNS (Winkel et al., 2020).

ChABC and antidepressant treatment exert similar plasticity-promoting effects in the adult brain; however, it is not known whether they recruit similar molecular mechanisms. We hypothesize that receptor-like protein tyrosine phosphatase $\sigma$ $(\mathrm{PTP} \sigma)$ might be a nexus that mediates plasticity processes induced by both methods. PTP $\sigma$ is a receptor for CSPGs (Shen et al., 2009), and it has been demonstrated to be essential for the inhibitory effects of CSPGs on neurite outgrowth (Shen et al., 2009; Duan and Giger, 2010; Coles et al., 2011). PTP $\sigma$ interacts with and modulates the activity of TRK receptors (Faux et al., 2007; Takahashi et al., 2011), inhibiting TRKB through dephosphorylation (Kurihara and Yamashita, 2012).

We now demonstrate that TRKB activity in $\mathrm{PV}^{+}$interneurons is essential for plasticity induced by chABC. While CSPGs removal by chABC injection into the visual cortex promotes ocular dominance shift, this effect is abolished in heterozygous mice with reduced TRKB in $\mathrm{PV}^{+}$neurons $\left(\mathrm{PV}-\mathrm{TRKB}^{+/-}\right)$. We have confirmed that $\mathrm{PTP} \sigma$ interacts with TRKB, and genetic deficiency of PTP $\sigma$ promotes TRKB phosphorylation (pTRKB) in vitro and in vivo. We further show that $\mathrm{PTP} \sigma$ deficiency promotes plasticity at network levels, as $\mathrm{PTP} \sigma^{+/-}$mice display critical period-like plasticity in the visual cortex in adulthood. Finally, we have observed that the antidepressant fluoxetine disrupts TRKB:PTP $\sigma$ interaction in vitro and in vivo.

\section{Materials and Methods}

Animals

$\mathrm{BALB} / \mathrm{c}$ and C57BL/6J mice heterozygous for PTPRS gene (PTP $\sigma^{+/-}$ mice) and their wild-type (WT) littermates, C57BL/6J mice heterozygous for TRKB gene in $\mathrm{PV}^{+}$interneurons $\left(\mathrm{PV}-\mathrm{TRKB}^{+/-}\right.$) and their PV-Cre littermates $\left(\mathrm{PV}-\mathrm{TRKB}^{+/+}\right)$, WT C57BL/6J mice were used in the experiments. $\mathrm{BALB} / \mathrm{c} \mathrm{PTP} \sigma^{+/-}$mice were originally developed by Michel Tremblay's lab (McGill University, Canada; Elchebly et al., 1999) and kindly donated to us by Heikki Rauvala (University of Helsinki). BALB/ c PTP $\sigma^{+/-}$mice 10 weeks old were used for brain sample collection and pTRKB level assessment by ELISA. For optical imaging experiments, $\mathrm{BALB} / \mathrm{c}$ mouse line was rederived to $\mathrm{C} 57 \mathrm{BL} / 6 \mathrm{~J}$ background, and $\mathrm{N} 4$ generation of the offspring was used for testing. The mice were two months old at the beginning of the experiments. PV-TRKB ${ }^{+/-}\left(\mathrm{TRKB}^{\mathrm{fl} / \mathrm{wt}}\right.$, $\left.\mathrm{PV}^{\mathrm{cre} / \mathrm{wt}}\right)$ mice were generated by mating heterozygous floxed TRKB mice $\left(\right.$ TRKB $^{\mathrm{flx} / \mathrm{wt}}$; Minichiello et al., 1999) and homozygous PV-specific Cre line (PV ${ }^{\text {cre/cre; }}$ Pvalb-IRES-Cre, JAX: 008069, The Jackson Laboratory; Hippenmeyer et al., 2005). PV heterozygous (TRKBw/w, $\mathrm{PV}^{\mathrm{cre} / \mathrm{wt}}$ ) littermates with intact TRKB in $\mathrm{PV}^{+}$neurons were used as a control group for PV-TRKB ${ }^{+/-}$mice. The mice were four months old at the beginning of the experiments. WT C57BL/6J mice five months old were used to assess fluoxetine effect on TRKB:PTP $\sigma$ interaction in the visual cortex in vivo. The mice were kept under standard laboratory conditions with $12 / 12 \mathrm{~h}$ light/dark cycle (lights on at 6 A.M.) and access to food and water ad libitum. All the procedures involving animals were done in compliance with the National Institutes of Health Guide for the Care and Use of Laboratory Animals guidelines and were approved by the Experimental Animal Ethical Committee of Southern Finland (ESAVI/10 300/04.10.07/2016).

Brain sample collection and processing

Mice were killed with $\mathrm{CO}_{2}$. The death was confirmed by ascertaining cardiac and respiratory arrest. The animals were decapitated, the visual cortices were dissected and stored at $-80^{\circ} \mathrm{C}$. Samples from the primary visual cortex were sonicated in NP lysis buffer (137 mM NaCl, $20 \mathrm{~mm}$ Tris, $1 \% \mathrm{NP}-40,10 \%$ glycerol, and $48 \mathrm{~mm} \mathrm{NaF}$ ) containing a protease and phosphatase inhibitor mix (\#P2714 and \#P0044, Sigma-Aldrich) and $2 \mathrm{mM} \mathrm{Na}_{2} \mathrm{VO}_{3}$. The homogenate was centrifuged for $15 \mathrm{~min}$ at $15,000 \times g, 4^{\circ} \mathrm{C}$. The supernatant was collected and used for further analysis. Protein levels were measured using DC Protein Assay kit (BioRad, \#5000116) by colorimetric Lowry method in Varioskan Flash (Thermo Fisher Scientific).

\section{Cell culture}

Cerebral cortical cell cultures were prepared from Wistar rat (Harlan Labs) embryos extracted on embryonic day (E)18 (Sahu et al., 2019). The cells were cultured in a serum-free neurobasal medium with supplements (1\% penicillin, 1\% L-glutamine, 2\% B-27) and collected after 7$9 \mathrm{~d}$ in vitro (DIV). For the experiments assessing the effect of PTP $\sigma$ genetic deficiency on $\mathrm{PTRKB}$ in vitro, cortical cell cultures were prepared from $\mathrm{BALB} / \mathrm{c}$ mouse embryos (PTP $\sigma^{-/-}, \mathrm{PTP} \sigma^{+/-}$and their WT littermates) extracted on E18 using the same protocol as described above for the rat cells. Mouse fibroblast cells stably expressing full-length TRKB (MG87.TRKB) or TRKA (MG87.TRKA) were cultured in DMEM supplemented with $10 \%$ fetal calf serum (FCS), $1 \%$ penicillin/streptomycin (PS), 1\% L-glutamine, and $400 \mathrm{mg} / \mathrm{ml} \mathrm{G418.} \mathrm{Human-derived} \mathrm{HEK293T}$ cells were cultured in DMEM supplemented with $10 \%$ FCS, $1 \%$ PS, and $1 \%$ L-glutamine.

\section{Transfection}

We transfected 70\% confluent MG87.TRKA, MG87.TRKB, and HEK293T cell lines using Lipofectamine 2000 (Thermo Fischer Scientific). MG87. TRKA and MG87.TRKB cells were transfected with PTP $\sigma$ (RefSeq number NM_019140) Myc-DDK-tagged open-reading frame (ORF) plasmid purchased from OriGene (\#RR209636), pCMV6-Entry vector with C-terminal Myc-DDK Tag (\#PS100001) was used to transfect control cells. HEK293T were transfected with GFP-tagged full-length TRKB plasmid (HP220GFPTRKB; Haapasalo et al., 2001) or TRKB carrying Y433F/R427A mutation (Cannarozzo et al., 2020).

Antibodies and reagents

Aggrecan was purchased from Sigma-Aldrich (A1960). Anti-phosphoTRKA (Tyr490)/TRKB (Tyr516; C35G9) rabbit monoclonal antibody 
Table 1. Statistical analysis and the number of animals/samples used in the experiments

\begin{tabular}{|c|c|c|c|}
\hline$\overline{G r a p h}$ & Pre hoc & Post hoc & $N$, number of samples/animals per group \\
\hline $1 A$ & $\begin{array}{l}\text { Three-way ANOVA (time } \times \text { genotype } \times \text { drug): } \\
\text { General effect: } \\
\text { Time }\left(\text { IOS): } F_{(1,34)}=4.139, p=0.0498^{*}\right. \\
\text { Genotype: } F_{(1,34)}=0.7739, p=0.3852 \\
\text { chABC: } F_{(1,34)}=5.164, p=0.0295^{*} \\
\text { Interaction: } \\
\text { Time } \times \text { genotype: } F_{(1,34)}=4.861, p=0.0343^{*} \\
\text { Time } \times \text { chABC: } F_{(1,34)}=6.483, p=0.0156^{*} \\
\text { Genotype } \times \text { chABC: } F_{(1,34)}=7.244, p=0.0110^{*} \\
\text { Time } \times \text { genotype } \times \text { chABC: } F_{(1,34)}=5.899, p=0.0206^{*}\end{array}$ & $\begin{array}{l}\text { Tukey's multiple comparison test: } \\
\text { WT-chABC (IOS1) } \times \text { WT-chABC (IOS2): } \\
\quad p=0.0002^{*}\end{array}$ & $\begin{array}{l}\text { WT-vehicle: } 3 \text { (we have used the lowest number of animals } \\
\text { possible in the control group to reduce the total number of } \\
\text { animals used in the experiments; there is abundant evi- } \\
\text { dence of no shift in ocular dominance in adult WT mice } \\
\text { both from our lab and in the literature) } \\
\text { WT-chABC: } 6 \\
\text { PV-TRKB } \\
\text { PV-TRKB }{ }^{+/-} \text {- } \text {-chABicle: } 5 \\
\text {-chAC: } 7\end{array}$ \\
\hline $1 B$ & Mann-Whitney: $U=0, p=0.0286^{*}$ & & $\begin{array}{l}\text { Vehicle: } 4 \\
\text { chABC: } 4\end{array}$ \\
\hline $1 C$ & $\begin{array}{l}\text { Two-way ANOVA: } \\
\text { Interaction: } F_{(1,20)}=3.921, p=0.0616 \\
\text { BDNF: } F_{(1,20)}=155.2, p<0.0001^{*} \\
\text { Aggrecan: } F_{(1,20)}=5.117, p=0.035^{*}\end{array}$ & $\begin{array}{l}\text { Tukey's multiple comparison test: } \\
\text { BDNF-vehicle } \times \text { BDNF-aggrecan: } \\
\quad p=0.0329^{*}\end{array}$ & $\begin{array}{l}\text { Vehicle-vehicle: } 6 \\
\text { Vehicle-aggrecan: } 6 \\
\text { Vehicle-BDNF: } 6 \\
\text { BDNF-aggrecan: } 6\end{array}$ \\
\hline $2 B$ & Unpaired $t$ test: $\mathrm{T}_{22}=4384, p=0.0002^{*}$ & & $\begin{array}{l}\text { WT: } 12 \\
\text { PTP } \sigma^{+/-}: 12\end{array}$ \\
\hline $2 C$ & $\begin{array}{l}\text { One-way ANOVA: } \\
F_{(2,14)}=91.44, p<0.0001^{*}\end{array}$ & $\begin{array}{l}\text { Tukey's multiple comparison test: WT } \times \\
\quad \text { PTP } \sigma^{+/-}: p=0.0007^{*} \\
\text { WT } \times \text { PTP } \sigma^{-1-}: p<0.0001^{*} \\
\text { PTP } \sigma^{+/-} \times \operatorname{PTP} \sigma^{-1-}: p<0.0001^{*}\end{array}$ & $\begin{array}{l}\text { WT: } 5 \\
\operatorname{PTP} \sigma^{+/-}: 6 \\
\operatorname{PTP} \sigma^{-1-}: 6\end{array}$ \\
\hline $2 D$ & Mann-Whitney: $U=0, p=0.0002^{*}$ & & $\begin{array}{l}\text { WT: } 7 \\
\text { PTP } \sigma^{+1-}: 9\end{array}$ \\
\hline $2 E$ & Mann-Whitney: $U=9, p=0.0164^{*}$ & & $\begin{array}{l}\text { WT: } 7 \\
\text { PTP } \sigma^{+/-}: 9\end{array}$ \\
\hline $2 F$ & $\begin{array}{l}\text { Two-way ANOVA: } \\
\text { Interaction: } F_{(1,8)}=33,13, p=0.0004^{*} \\
\text { Time: } F_{(1,8)}=40.81, p=0.0002^{*} \\
\text { Genotype: } F_{(1,8)}=36.70, p=0.0003^{*}\end{array}$ & $\begin{array}{l}\text { Bonferroni's multiple comparison test: } \\
\text { IOS1-PTP } \sigma^{+1-} \times \text { IOS2- PTP } \sigma^{+1-}: \\
\quad p=0.0001^{*}\end{array}$ & $\begin{array}{l}\text { WT: } 6 \\
\text { PTP } \sigma^{+/-}: 4\end{array}$ \\
\hline $3 A$ & $\begin{array}{l}\text { One-way ANOVA: } \\
F_{(2,15)}=6.734, p=0.0082^{*}\end{array}$ & $\begin{array}{l}\text { Bonferroni's multiple comparison test: } \\
\text { vehicle } \times \text { fluoxetine } 1 \mu \mathrm{m}: p=0.0046^{*}\end{array}$ & $\begin{array}{l}\text { Vehicle: } 6 \\
\text { Fluoxetine } 0.1 \mu \mathrm{m}: 6 \\
\text { Fluoxetine } 1 \mu \mathrm{m}: 6\end{array}$ \\
\hline $3 B$ & Unpaired $t$ test: $t_{(6)}=4.025, p=0.0069^{*}$ & & $\begin{array}{l}\text { Vehicle: } 4 \\
\text { Fluoxetine: } 4\end{array}$ \\
\hline $3 C$ & Unpaired $t$ test: $t_{(28)}=0.9872, p=0.3320$ & & $\begin{array}{l}\text { Vehicle: } 15 \\
\text { Fluoxetine: } 15\end{array}$ \\
\hline $3 D$ & $\begin{array}{l}\text { Two-way ANOVA: } \\
\text { Interaction: } F_{(1,19)}=0.8761, p=0.3610 \\
\text { Fluoxetine: } F_{(1,19)}=2.627, p=0.1216 \\
\text { TRKB mutation: } F_{(1,19)}=5.131, p=0.0354^{*}\end{array}$ & & $\begin{array}{l}\text { WT-TRKB-vehicle: } 6 \\
\text { WT-TRKB-fluoxetine: } 6 \\
\text { Mutant TRKB-vehicle: } 5 \\
\text { Mutant TRKB-fluoxetine: } 6\end{array}$ \\
\hline
\end{tabular}

* Statistically significant.

(mAb) was purchased from Cell Signaling Technology (\#4619, \#4621, and \#4168). Anti-TRKB goat polyclonal antibody (pAb) was bought from R\&D Systems, \#AF1494. Anti-phosphotyrosine mouse monoclonal antibody (clone PY20) was purchased from Bio-Rad (\#MCA2472). AntiPTP $\sigma$ (SS-8) mAb was purchased from Santa Cruz Biotechnology (SC-100419). Secondary horseradish peroxidase (HRP)-conjugated antibodies were purchased from Bio-Rad (goat anti-rabbit \#1705046 and goat anti-mouse \#1705047) and from Invitrogen (rabbit anti-goat \#611620). Enhanced chemiluminescent (ECL) substrate WesternBright Quantum HRP substrate (Advansta) was used for Western blotting (\#K-12042). Pierce HRP ECL substrate was used to detect luminescence in ELISA (Thermo Fisher Scientific, \#32209). Tris-buffered saline with Tween 20 (TBST) was used for Western blotting ( $20 \mathrm{~mm}$ Tris-HCl, 150 $\mathrm{mm} \mathrm{NaCl}$, and $0.1 \%$ Tween 20; pH 7.6), PBS with Tween 20 (PBST) was used for ELISA ( $137 \mathrm{~mm} \mathrm{NaCl}, 10 \mathrm{~mm}$ phosphate, $2.7 \mathrm{~mm} \mathrm{KCl}$, and $0.1 \%$ Tween 20; pH 7.4)

\section{Drug treatment}

We added $10 \mu \mathrm{g} / \mathrm{ml}$ aggrecan to cortical neurons cultured 6 DIV, and the cells were collected $1 \mathrm{~d}$ after the aggrecan treatment (7 DIV); $20 \mathrm{ng} /$ $\mathrm{ml} \mathrm{BDNF}$ was added to cortical cells for $10 \mathrm{~min} ; 0.1$ and $1 \mu \mathrm{M}$ fluoxetine was added to cortical cells cultured 7 DIV, and the cells were collected after $30 \mathrm{~min}$ of treatment. HEK293T cells were treated with $10 \mu \mathrm{M}$ fluoxetine for $30 \mathrm{~min}$. BALB/c PTP $\sigma^{+/-}$and WT mice were injected with $30 \mathrm{mg} / \mathrm{kg}$ fluoxetine intraperitoneally and killed with $\mathrm{CO}_{2}$. The brain samples were collected and stored at $-80^{\circ} \mathrm{C}$ until further processing.

\section{Immunoprecipitation and Western blotting}

The cells were lysed using NP lysis buffer containing $2 \mathrm{~mm}$ sodium orthovanadate and protease inhibitor mix. The homogenized suspension was centrifuged $\left(15,000 \times g, 10 \mathrm{~min},+4^{\circ} \mathrm{C}\right)$, and the resulting supernatant was used for analysis. For immunoprecipitation, TRKB was captured using anti-TRKB antibodies (R\&D Systems). The samples were incubated with Sepharose, washed with NP lysis buffer twice and the proteins were separated by heating in $2 \times$ Laemmli buffer (4\% SDS, $20 \%$ glycerol, 10\% 2-mercaptoethanol, $0.02 \%$ bromophenol blue, and $125 \mathrm{~mm}$ Tris $\mathrm{HCl} ; \mathrm{pH} 6.8$ ) for $5 \mathrm{~min}$ at $95^{\circ} \mathrm{C}$. The samples were loaded to NuPAGE 4-12\% Bis-Tris Protein polyacrylamide gels (Invitrogen, \#NP0323BOX), and the proteins were separated according to their molecular weight using electrophoresis. The samples were transferred to polyvinylidene difluoride (PVDF) membrane, incubated in 1:1000 primary antibody dilution in 3\% bovine serum albumin (BSA) in tris-phosphate buffer containing $0.1 \%$ Tween 20 (TBST) overnight at $4^{\circ} \mathrm{C}$ and subsequently incubated in HRP-conjugated secondary antibodies $(1: 10,000)$ for $1 \mathrm{~h}$ at room temperature $(\mathrm{RT})$. The bands were visualized 
A

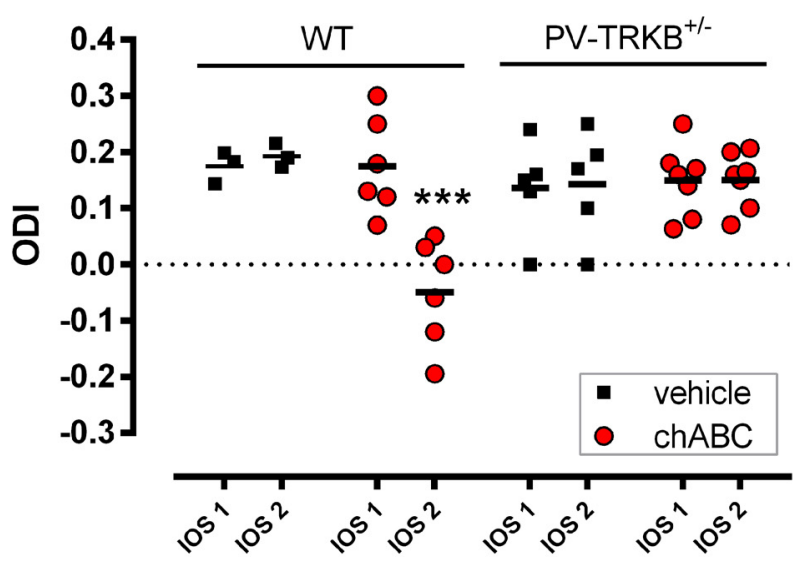

B

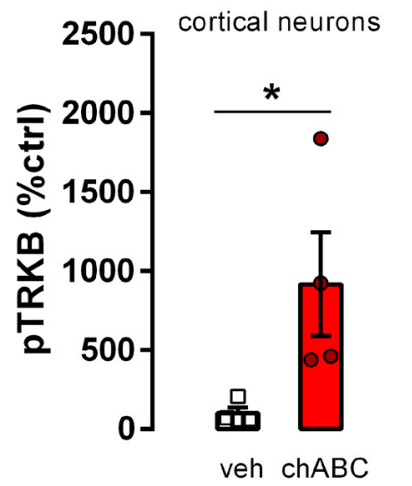

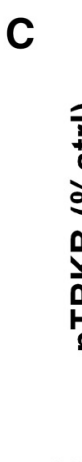

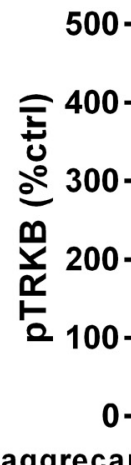

aggrecan cortical neurons

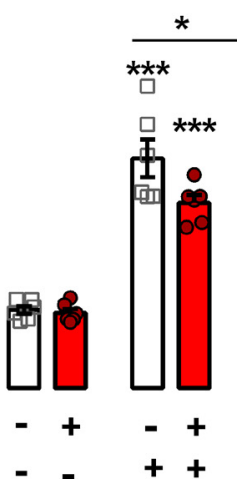

Figure 1. ChABC-induced plasticity requires intact TRKB signaling in $\mathrm{PV}^{+}$neurons. $A$, PNN removal by local chABC injection reopens critical period-like plasticity in the visual cortex of WT but not in mice heterozygous for TRKB deletion in PV interneurons $\left(\right.$ PV-TRKB $\left.^{+/-}\right)$, as measured by optical imaging of the intrinsic signal before (IOS1) and after $7 \mathrm{~d}$ of MD (IOS2). ODI: ocular dominance index. $\boldsymbol{B}$, ChABC treatment $(30 \mathrm{~min}$ ) of cortical neurons (7 DIV) increases PTRKB. C, The CSPG aggrecan, added to cortical neurons (6 DIV) for $24 \mathrm{~h}$, attenuates BDNF-induce PTRKB in cortical neurons. Columns and bars represent mean \pm SEM, respectively, and scattered points represent individual values. Data were analyzed by three-way ANOVA and Tukeys's post hoc $(\boldsymbol{A})$, Mann-Whitney $(\boldsymbol{B})$, or two-way ANOVA followed by Tukey's multiple comparison test (C); *p<0.05,**p<0.005, ***p $<0.0005$.

using chemiluminescent western blotting substrate in Fuji LAS3000 camera (Tamro Medlabs).

\section{ELISA}

Levels of pTRKB were evaluated using ELISA for pTRKB developed in our lab (Antila et al., 2014). On day 1, the high-binding 96-well OptiPlate (PerkinElmer) was incubated overnight at $4^{\circ} \mathrm{C}$ with 1:500 antiTRKB antibody diluted in a homemade carbonate buffer ( $57.4 \mathrm{~mm}$ sodium bicarbonate and $42.6 \mathrm{~mm}$ sodium carbonate, $\mathrm{pH} 9.8$ ). On day 2, the plate was incubated for $2 \mathrm{~h}$ at RT in the blocking buffer (3\% BSA in PBST) to block non-specific binding. Homogenized and centrifuged brain samples or lysed cell samples were added to the plate and incubated overnight at $4^{\circ} \mathrm{C}$. On day 3 , the plate was washed four times with PBST using an automated plate washer (Thermo Fisher Scientific Wellwash Versa), and the samples were incubated in anti-phosphotyrosine or anti-pTRKB antibodies diluted 1:1000 in the blocking buffer overnight at $4^{\circ} \mathrm{C}$. On day 4 , the samples were washed four times in PBST and incubated with tertiary HRP-conjugated antibodies in the blocking buffer (1:5000) at RT for $1 \mathrm{~h}$. Finally, ECL was added to the plate and luminescence was measured with 1-s integration time using Varioskan Flash plate reader (Thermo Fisher Scientific). Levels of TRKB:PTP $\sigma$ interaction were evaluated by ELISA using a similar protocol. TRKB was captured using anti-TRKB antibodies, and anti-PTP $\sigma$ were applied afterward to assess levels of PTP $\sigma$ bound to TRKB.

\section{Cell-surface ELISA}

Cell-surface ELISA was conducted to assess PTP $\sigma$ levels found on the cell surface as previously described (Zheng et al., 2008; Fred et al., 2019).

Briefly, cortical cells were cultivated in clearbottom 96-well plates (ViewPlate 96, PerkinElmer). On 7 DIV, the cells' medium was removed, washed with cold PBS, and fixed with $100 \mu \mathrm{l}$ of $4 \%$ paraformaldehyde (PFA) per well for $20 \mathrm{~min}$. Then the cells were washed with $\mathrm{PBS}$ three times, and non-specific binding was blocked with PBS containing $5 \%$ non-fat dry milk and 5\% BSA for $1 \mathrm{~h}$ at RT. After that, the samples were incubated in primary anti-PTP $\sigma$ antibody (1:500 in the blocking buffer) overnight at $4^{\circ} \mathrm{C}$. On the following day, the cells were washed with PBS once and incubated in HRP-conjugated antimouse antibody (1:5000 in the blocking buffer) for $1 \mathrm{~h}$ at RT. The cells were washed four times with PBS, ECL was added and chemiluminescence was measured with 1-s integration time using Varioskan Flash (Thermo Fisher Scientific).

\section{Transparent skull surgery}

Transparent skull surgery was conducted as described previously (Steinzeig et al., 2017). Animals were anesthetized either with a mixture of $0.05 \mathrm{mg} / \mathrm{kg}$ fentanyl (Hameln), $5 \mathrm{mg} /$ $\mathrm{kg}$ midazolam (Hameln), and $0.5 \mathrm{mg} / \mathrm{kg}$ medetomidine (Orion Pharma) administered intraperitoneally or isoflurane combined with $0.05 \mathrm{mg} / \mathrm{kg}$ buprenorphine analgesia administered subcutaneously, $5 \mathrm{mg} / \mathrm{kg}$ carprofen (ScanVet) was administered subcutaneously for postoperative analgesia. Under anesthesia, the scalp and periosteum of the animals were removed, the skull was polished, and two layers of transparent acryl powder (EUBECOS) mixed with methyl methacrylate liquid (Dentsply) were applied on the surface. Metal holders (Neurotar) were installed on the top of the head and fixed with a mixture of acryl polymer powder (Dentsply) and cyanoacrylate glue (Steinzeig et al., 2017).
Monocular deprivation (MD)

MD was conducted by suturing the eye contralateral to the imaged hemisphere (left eye) with perma-hand silk thread (Ethicon). The length of the MD was $3.5 \mathrm{~d}$ for the PTP $\sigma^{+/-}$versus WT experiment and $7 \mathrm{~d}$ for the PV-TRKB ${ }^{+/-}$versus WT experiment. The integrity of the suture was checked on a daily basis before the lights were on.

\section{Optical imaging}

Optical imaging of intrinsic signals was conducted as previously described (Steinzeig et al., 2017). Visual cortex of the right hemisphere of each animal was imaged. Continuous-periodic stimulation with continuous synchronized data acquisition was used for the processing of the intrinsic signals. A drifting thin horizontal bar $2^{\circ}$ wide moving upwards with a temporal frequency of 1 cycle $/ 8.3 \mathrm{~s}(0.125 \mathrm{~Hz})$ and a spatial frequency of $1 / 80^{\circ}$ was used to alternatively stimulate the left and right eye, while the other eye was patched. The drifting bars were displayed $-15^{\circ}$ to $+5^{\circ}$ from the center to optimally stimulate the binocular area of the right visual cortex. The imaging was done under $1.2 \%$ isoflurane anesthesia in a 1:2 mixture of $\mathrm{O}_{2}$ :air.

Optical imaging of $P V-T R K B^{+/-}$mice

Four-month-old mice were used for the experiments. During week 1, the animals underwent transparent skull surgery. After $7 \mathrm{~d}$, during week 2 , the animals underwent the first session of the optical imaging under isoflurane anesthesia (IOS1). During week 3, the animals were injected with $50 \mathrm{mU}$ of chABC in PBS or PBS into the binocular area of the visual 
A

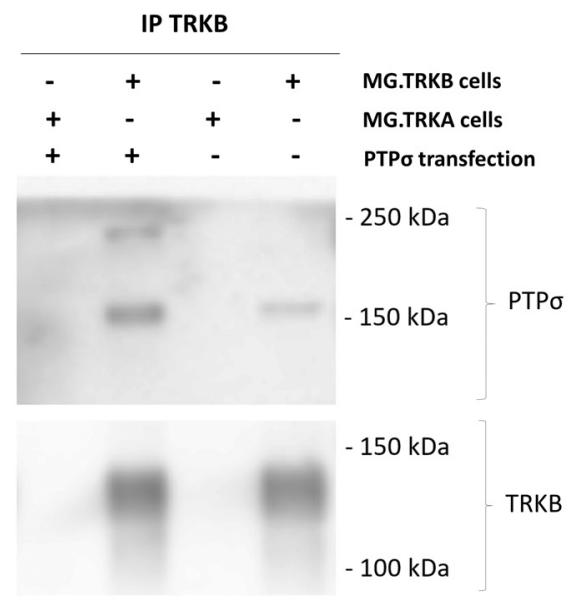

B

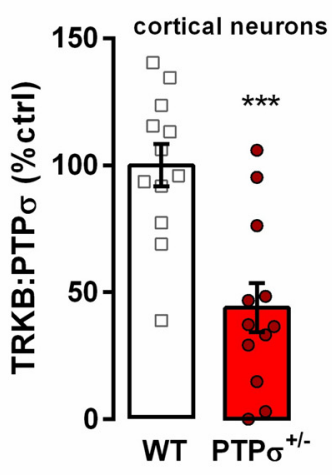

C

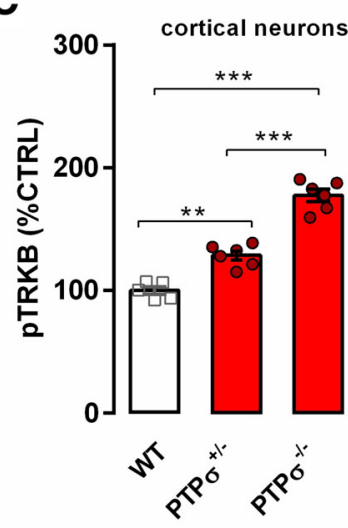

D

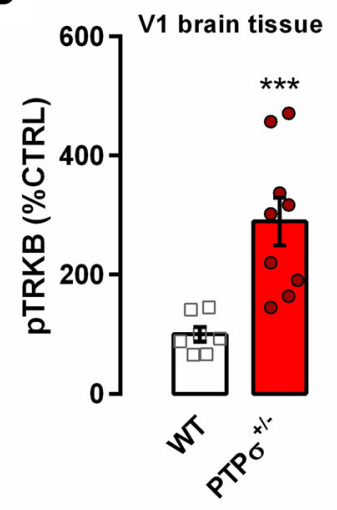

E

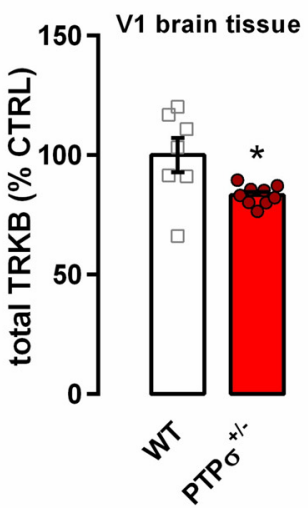

$\mathbf{F}$

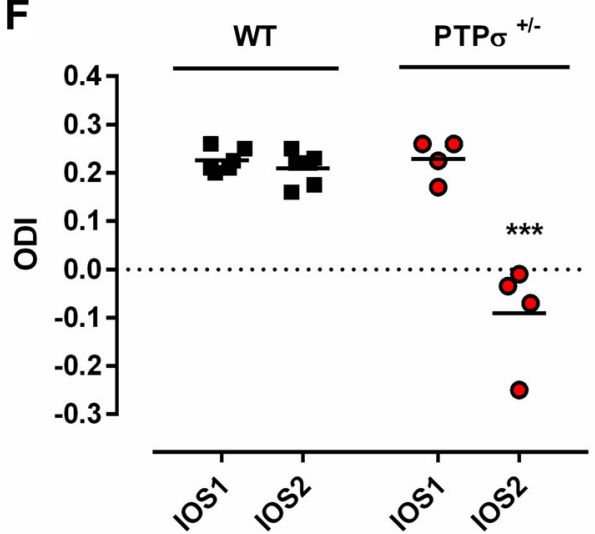

Figure 2. Deletion of CSPG receptor PTP $\sigma$ facilitates PTRKB and delays closure of the critical period in the visual cortex of adult mice. $\boldsymbol{A}$, PTP $\sigma$ can be immunoprecipitated with anti-TRKB antibody in samples from a TRKB-expressing, but not from a TRKA-expressing, cell line. $\boldsymbol{B}$, Interaction of TRKB and PTP $\sigma$ is reduced in embryonic cortical cultures from PTP $\sigma^{+/-}$mice when compared with those from WT mice. C, pTRKB is increased in cortical cultures from PTP $\sigma^{+/-}$and PTP $\sigma^{-1-}$ mice. $\boldsymbol{D}$, Adult PTP $\sigma^{+/-}$mice have increased pTRKB and (E) a slight decrease in total TRKB levels in the visual cortex. $\boldsymbol{F}$, Critical period-like plasticity is present in the visual cortex of two-month-old PTP $\sigma^{+/-}$mice (red circles) but not in WT littermates (black squares), as measured by optical imaging of the intrinsic signal before (IOS1) and after $3.5 \mathrm{~d}$ of MD (IOS2). ODI: ocular dominance index. Columns and bars represent mean \pm SEM, respectively, and scattered points represent individual values. Data were analyzed by two-way $(\boldsymbol{F})$ or one-way ANOVA $(\boldsymbol{C})$ followed by Bonferroni's or Tukey's post hoc, respectively; unpaired $t$ test $(\boldsymbol{B})$ or MannWhitney test $(\boldsymbol{D}, \boldsymbol{E}) ; * p<0.05, * * p<0.005, * * * p<0.0005$.

cortex and were subjected to MD for $7 \mathrm{~d}$. During week 4 , the eyes were opened, and IOS2 immediately took place.

Optical imaging of PTP $\sigma^{+/-}$mice

Two-month-old mice were used for the experiments. During week 1, the animals underwent transparent skull surgery. After $7 \mathrm{~d}$, the animals underwent the first session of the optical imaging (IOS1) followed by MD for $3.5 \mathrm{~d}$. We have switched to the shorter MD length as compared with the previously described experiment since it has been recently demonstrated to be sufficient for the induction of the critical period-like plasticity (Baho et al., 2019). On day 4 of the MD, the eyes were opened, and IOS2 took place.

\section{Stereotaxic surgeries}

The mice were anesthetized with isoflurane combined with $0.05 \mathrm{mg} / \mathrm{kg}$ buprenorphine analgesia. Images acquired during the first session of the optical imaging were used to identify the binocular area of the visual cortex. A hole in the skull was made with a drill, and $50 \mathrm{mU}$ of chABC in $1 \mu \mathrm{l}$ of PBS or $1 \mu \mathrm{l}$ of PBS was injected in the center of the binocular area using a microsyringe pump; $10-\mu$ l Nanofil syringe (WPI Nanofil) with drilled $1.1-\mathrm{mm}$ outlet bore to accommodate $1.0-\mathrm{mm}$ glass needle and custom-made bevelled borosilicate glass needles with a $50-\mu \mathrm{m}$ tip diameter were used for the infusions. Infusions were done at the speed of $2 \mathrm{nl} /$ s. After the surgery, the animals were left to recover in the home cage, and the second imaging session took place $7 \mathrm{~d}$ later.
Experimental design and statistical analysis

The experiments were designed taking into account good laboratory practices and the $3 \mathrm{Rs}$ principle of animal research. Both sexes of mice were used in all the experiments involving animal testing, except for the in vivo fluoxetine experiment (samples from only male mice were used because of a low number of female mice available in the cohort). Parametric tests were preferentially used to gain statistical power. Exceptions were made whenever the data presented lacked homoscedasticity or when variables were discrete, in which cases non-parametric tests were chosen. The statistical tests used in each particular experiment and statistical values are described in the legend of figures, and statistical values are provided in Table 1. Differences were considered statistically significant when $p<0.05$. Statistical analysis and plots were made in GraphPad Prism 6 software. Data are presented as mean \pm SEM. Detailed information on the statistical analysis of each experiment, and number of samples/animals used is given in Table 1.

\section{Results}

TRKB signaling in $\mathrm{PV}^{+}$neurons is essential for chABCinduced plasticity

Digestion of PNNs by chABC is a well-known activator of plasticity (Fawcett et al., 2019), and it has been shown to induce critical period-like plasticity in the adult rodent visual cortex through 
A

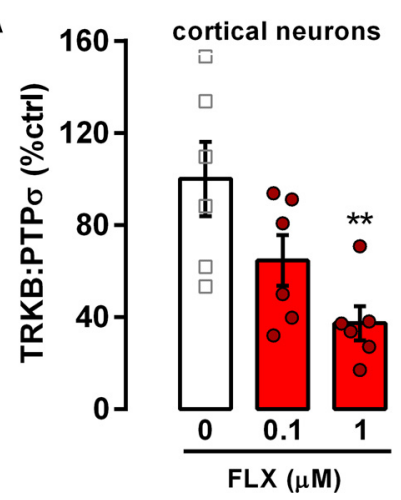

C

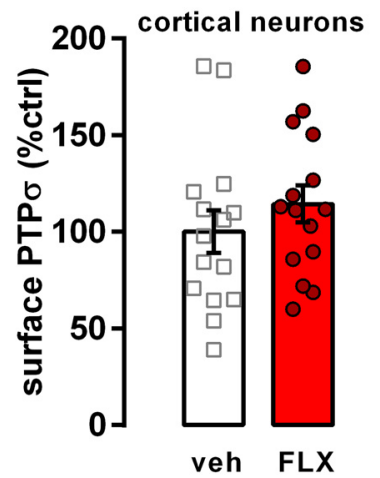

B

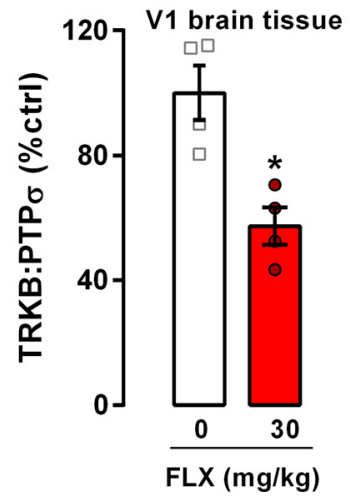

D

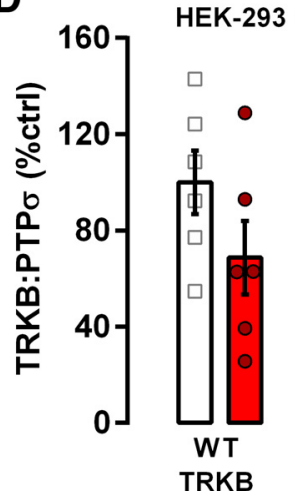

$\mathrm{ml}$ chABC for $30 \mathrm{~min}$ and checked the activation of TRKB by assessing its phosphorylation levels (pTRKB; Antila et al., 2014). We observed that reduction of $\mathrm{PNNs}$ by chABC treatment robustly increased $\mathrm{pTRKB}$ in vitro (Fig. $1 B$ ).

After observing that PNN digestion with chABC treatment positively affects pTRKB, we investigated whether treatment with aggrecan, a major PNN component in the adult CNS, might have an opposing effect on pTRKB and render BDNF-induced TRKB activation less effective. We added $10 \mu \mathrm{g} / \mathrm{ml}$ aggrecan to the primary cortical neurons cultured for 6 DIV. After $24 \mathrm{~h}$, we challenged the cells with $20 \mathrm{ng} /$ $\mathrm{ml} \mathrm{BDNF}$ for $10 \mathrm{~min}$. Aggrecan treatment did not alter basal pTRKB levels (that are normally very low in vitro); however, it significantly decreased BDNF-induced pTRKB (Fig. 1C). Taken together, these data demonstrate that PNNs regulate plasticity in a TRKB-dependent manner in vivo and that PNNs exert negative effects on TRKB activation in vitro.

\section{Deletion of CSPG receptor PTP $\sigma$ extends the critical period and facilitates TRKB activation}

PTP $\sigma$ is a recognized inhibitor of neuronal plasticity and a receptor for CSPGs (Shen et al., 2009; Duan and Giger, 2010; Fawcett et al., 2019), and previous data indicate that PTP $\sigma$ interacts with TRKB (Kurihara and Yamashita, 2012). We therefore hypothesized that $\mathrm{PTP} \sigma$ might restrict TRKB signaling through dephosphorylation in PNN-bearing $\mathrm{PV}^{+}$interneurons and thereby inhibit TRKBpromoted plasticity. To confirm TRKB:PTP $\sigma$ interaction, NIH3T3 cell line stably expressdegradation of CSPGs in the extracellular matrix (Pizzorusso et al., 2002). However, precise molecular mechanisms responsible for the plasticity-promoting effect of chABC remain largely unknown.

We tested the hypothesis that TRKB functioning in $\mathrm{PV}^{+}$ interneurons is involved in chABC-induced plastic changes. For that purpose, we generated mice heterozygous for full-length TRKB allele in $\mathrm{PV}^{+}$interneurons $\left(\mathrm{PV}-\mathrm{TRKB}^{+/-}\right.$; Minichiello et al., 1999). We assessed the ability of chABC to promote ocular dominance plasticity in their visual cortex. Four-month-old mice underwent assessment of their ocular dominance by optical imaging of the intrinsic signal (IOS1; Cang et al., 2005; Steinzeig et al., 2017). After the first imaging session, the mice were injected with chABC or vehicle into the binocular area of the visual cortex followed by MD for $7 \mathrm{~d}$. As expected, vehicle-treated WT mice failed to show any OD plasticity in the second imaging session (IOS2) right after the MD, whereas WT mice treated with chABC showed a clear shift in the ocular dominance toward the non-deprived eye (Fig. $1 A$ ), as previously shown (Pizzorusso et al., 2002). However, PV-TRKB ${ }^{+/-}$mice failed to show any shift in ocular dominance regardless of whether they were treated with chABC or not (Fig. 1A). These data demonstrate that chABC-mediated reactivation of visual cortical plasticity is dependent on intact TRKB signaling in the $\mathrm{PV}^{+}$interneurons.

Next, we assessed whether PNN digestion with chABC induces TRKB activation in primary cerebral cortical neurons. We treated rat cortical neurons grown in vitro (DIV) for $7 \mathrm{~d}$ with $2 \mathrm{U} /$ tively), were transfected with myc-PTP $\sigma$, immunoprecipitated with anti-TRKB antibody and blotted for PTP $\sigma$. In the transfected samples, we observed a band below $250 \mathrm{kDa}$ (Fig. 2A), which is consistent with the predicted molecular weight of the plasmid's product. Additionally, a $165-\mathrm{kDa}$ band was observed in non-transfected cells, which corresponds to the endogenous mature full-length PTP $\sigma$ (Faux et al., 2007). When the membrane was stripped and reblotted for TRKB, we observed a band of 140 $\mathrm{kDa}$ corresponding to the full-length TRKB. This band was seen in TRKB expressing cells only, which rules out potential unspecific binding of TRKB antibodies to TRKA receptors. These data indicate that PTP $\sigma$ interacts with TRKB. Furthermore, our previous proteomic study found $\mathrm{PTP} \sigma$ among the proteins that were immunoprecipitated with TRKB in hippocampal samples of the adult mouse brain (Fred et al., 2019).

Next, we set out to investigate the role of PTP $\sigma$ in pTRKB by using mice heterozygous for PTP $\sigma\left(\mathrm{PTP} \sigma^{+/-}\right)$. Since transgenic mice quite often develop compensatory mechanisms to counteract genetic deficiency, we wanted to confirm that neurons lacking PTPRS allele would present comparable reduction in PTP $\sigma$ : TRKB protein interaction. We prepared E18 neuronal cultures from cortex of WT or PTP $\sigma^{+/-}$littermates, and compared them after 7 DIV using co-immunoprecipitation. We observed a reduction of $\sim 50 \%$ in the interaction between TRKB and PTP $\sigma$ in samples from PTP $\sigma^{+/-}$mice as compared with WT (Fig. 2B). ing either TRKA or TRKB (MG.TRKA and MG.TRKB, respec- 

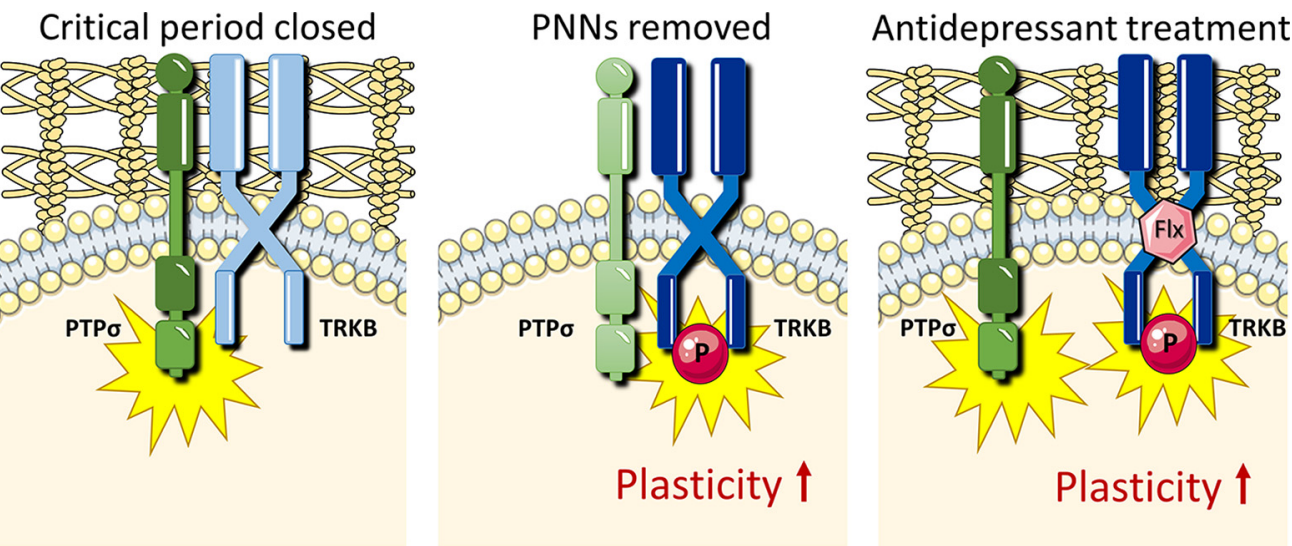

Figure 4. Schematic model of how chondroitinase and antidepressant treatments promote plasticity by releasing TRKB from dephosphorylating control of PTP $\sigma$. Left, In the presence of PNNs, active PTP $\sigma$ dephosphorylates TRKB and suppresses its signaling. Middle, In the absence of PNNs, PTP $\sigma$ is inactive and pTRKB is facilitated. Right, Fluoxetine (FLX) disrupts TRKB:PTP $\sigma$ interaction, promoting TRKB signaling.

Then, we further investigated whether PTP $\sigma$ influences pTRKB. We compared cortical pTRKB levels in embryonic cultures from $\mathrm{PTP} \sigma^{-1-}$ and PTP $\sigma^{+/-}$mice with those in cultures prepared from their WT littermates. Notably, PTP $\sigma$ had a clear gene dosage-dependent suppressive effect on the basal pTRKB. PTP $\sigma^{+/-}$ cortical cultures demonstrate increased pTRKB as compared with cultures from their WT littermates, and PTP $\sigma^{-1-}$ samples demonstrate yet further increased pTRKB significantly differing from both PTP $\sigma^{+/-}$and WT samples (Fig. 2C). We also checked the levels of pTRKB in samples from the adult visual cortex of mice heterozygous for PTPRS gene $\left(\mathrm{PTP} \sigma^{+/-}\right)$. In line with our in vitro data, adult $\mathrm{PTP} \sigma^{+/-}$mice exhibit increased basal TRKB autophosphorylation in the visual cortex (Fig. 2D), despite having slightly reduced levels of total TRKB (Fig. 2E), which may represent a compensatory downregulation because of a longterm increase in pTRKB.

Finally, we investigated whether increased TRKB signaling produced by genetic deficiency of PTP $\sigma$ might render the cortical structures of PTP $\sigma^{+/-}$mice susceptible to plastic changes. We tested adult PTP $\sigma^{+/-}$mice and their WT littermates in an ocular dominance plasticity paradigm using optical imaging. As expected, MD did not induce an ocular dominance shift in adult WT animals; however, it did induce a shift in ocular dominance in PTP $\sigma^{+/-}$mice (Fig. $2 F$ ), indicating that closure of the critical period was delayed or prevented in the PTP $\sigma^{+/-}$mice.

\section{Antidepressant treatment disrupts TRKB:PTP $\sigma$ interaction}

Antidepressants have been demonstrated to induce activation of TRKB receptors in the brain (Saarelainen et al., 2003; Rantamäki et al., 2007; Castrén and Rantamäki, 2010). Moreover, fluoxetine, a widely used antidepressant, induces ocular dominance plasticity in the adult visual cortex through BDNF-TRKB signaling (Maya Vetencourt et al., 2008) and reduces percentage of PNNs enwrapping $\mathrm{PV}^{+}$interneurons in the amygdala and hippocampus, shifting $\mathrm{PV}^{+}$interneurons toward an immature state and reopening brain plasticity (Karpova et al., 2011). Therefore, we asked whether fluoxetine treatment might have an effect on TRKB:PTP $\sigma$ interaction, which could potentially establish a link between antidepressant-induced pTRKB and PNNs. We cultured rat primary cortical neurons for 7 DIV and challenged them with two different doses of fluoxetine $(0.1$ and $1 \mu \mathrm{M})$ for $30 \mathrm{~min}$. Fluoxetine dose-dependently reduced the interaction between TRKB and PTP $\sigma$ in vitro as measured by ELISA (Fig. 3A). Since fluoxetine has been shown to increase pTRKB as fast as $30 \mathrm{~min}$ after systemic injection (Saarelainen et al., 2003), we checked whether fluoxetine would be able to disrupt TRKB:PTP $\sigma$ interaction in vivo within a similar timeframe. We treated animals with $30 \mathrm{mg} / \mathrm{kg}$ fluoxetine (intraperitoneally) and killed the animals $30 \mathrm{~min}$ after the injection. Acute fluoxetine treatment significantly reduced TRKB:PTP $\sigma$ interaction in vivo (Fig. $3 B$ ).

$\mathrm{PTP} \sigma$ is proteolytically processed by cleavage in the juxtamembrane region, leading to shedding of the extracellular domain (Faux et al., 2007). To rule out the possibility that TRKB: PTP $\sigma$ interaction experiments could have been influenced by a potential effect of the treatment on PTP $\sigma$ shedding, we investigated the presence of PTP $\sigma$ extracellular domain in the cell surface after fluoxetine treatment in cortical cells using cell-surface ELISA (Zheng et al., 2008; Fred et al., 2019). We found no effect of the drug (Fig. 3C). These data indicate that fluoxetine does not affect PTP $\sigma$ shedding and positioning on cell surface, and supports the idea that the decrease in PTP $\sigma$ levels in co-IP experiments is a result of decreased interaction with TRKB.

Antidepressants have recently been shown to directly interact with TRKB through the transmembrane region (Casarotto et al., 2019). Moreover, it has been previously suggested that PTP $\sigma$ interacts with TRKA receptors through its transmembrane region (Faux et al., 2007). Therefore, we asked whether disruption in TRKB:PTP $\sigma$ interaction after fluoxetine treatment is potentially mediated by the antidepressant's binding to the same region of TRKB where interaction with PTP $\sigma$ takes place. We transfected HEK293T cells with either a WT TRKB plasmid or a TRKB plasmid carrying two point mutations in the transmembrane region of TRKB (arginine R427 mutated to alanine, R427A; and tyrosine Y433 mutated to phenylalanine, Y433F); these point mutations disrupt a cholesterol interaction site in the TRKB transmembrane region critical for antidepressant interaction (Cannarozzo et al., 2020). R427A/Y433F mutation caused a dramatic decrease in TRKB:PTP $\sigma$ interaction levels, however, the interaction was not completely lost, suggesting that multiple sites of interaction may exist. Nevertheless, fluoxetine $(10 \mu \mathrm{M})$ failed to influence TRKB:PTP $\sigma$ interaction in the cells carrying R427A/Y433F mutated TRKB (Fig. 3D), providing evidence that the site of interaction of PTP $\sigma$ and fluoxetine with TRKB lies within the transmembrane region of TRKB.

\section{Discussion}

In the current study, we have investigated a possible convergence of the two plasticity-inducing methods, chABC and antidepressant 
treatment, on the same molecular pathway involving reduced dephosphorylation of TRKB by PTP $\sigma$ within $\mathrm{PV}^{+}$interneurons. PNNs, extracellular structures rich in CSPGs, are associated with a reduction of plasticity in the adult brain. Maturation of PNNs coincides with the closure of the critical period (Berardi et al., 2004; Fawcett et al., 2019), and digestion of PNNs has been shown to promote plasticity and re-open critical periods for certain functions in the adult nervous system (Fawcett et al., 2019). Local injections of chABC promote axonal regeneration and functional recovery after spinal cord injury (Bradbury et al., 2002), restore ocular dominance plasticity in the visual cortex (Pizzorusso et al., 2002), and promote extinction of fear memories in rodents (Gogolla et al., 2009). PNNs preferentially enwrap $\mathrm{PV}^{+}$interneurons that synchronize oscillatory activity of brain networks and mediate neuronal plasticity and learning. Our experiments demonstrate that the effects of chABC depend on TRKB signaling in $\mathrm{PV}^{+}$interneurons, since genetic deficiency of TRKB in $\mathrm{PV}^{+}$cells abrogates the ability of chABC to induce plasticity in the visual cortex of adult mice. Moreover, we have shown that chABC treatment increases pTRKB, which promotes TRKB signaling, while treatment with CSPG aggrecan decreases phosphorylation of TRKB induced by BDNF.

CSPGs, major components of PNNs, have been shown to exert inhibitory action on plasticity through protein tyrosine phosphatase receptor type S (Shen et al., 2009). PTP $\sigma$ has been demonstrated to be critical for the inhibitory effects of CSPGs on plasticity and regeneration since CSPGs exert little inhibitory effect on axonal outgrowth of neurons prepared from PTP $\sigma^{-1-}$ mice as compared with WT (Shen et al., 2009). Interestingly, $\mathrm{PTP} \sigma$ has been shown to interact with and dephosphorylate all three TRK receptors and inhibit their activation even in the presence of their cognate neurotrophins (Faux et al., 2007). Faux et al. (2007) provided evidence that PTP $\sigma$ forms stable complexes with TRKA and TRKC and only weakly interacts with TRKB. However, subsequent research has shown that PTP $\sigma$ co-immunoprecipitates with TRKB in samples from cortical neurons and mediates abrogation of BDNF-induced dendritic spine formation by CSPGs (Kurihara and Yamashita, 2012). We have now demonstrated that PTP $\sigma$ dephosphorylates TRKB in vitro and in vivo based on increased phosphorylation of TRKB in cultures prepared from $\mathrm{PTP} \sigma \mathrm{KO}$ homozygous or heterozygous mice $\left(\mathrm{PTP} \sigma^{-1-}\right.$ and PTP $\left.\sigma^{+/-}\right)$and in samples from the visual cortex of PTP $\sigma^{+/-}$mice. Moreover, we observed that genetic deficiency of PTP $\sigma$ delays the closure of critical period-like plasticity in the adult visual cortex, an effect that we demonstrated to be dependent on $\mathrm{TRKB}$ in $\mathrm{PV}^{+}$neurons.

TRKB signaling is known to be critical for activation of plasticity by antidepressant drug treatment and for the behavioral consequences of it (Saarelainen et al., 2003; Duman and Monteggia, 2006; Autry and Monteggia, 2012; Castrén and Antila, 2017). Moreover, our group has recently demonstrated that TRKB activation in $\mathrm{PV}^{+}$interneurons is sufficient for the induction of juvenile-like plasticity in the adult brain and necessary for the plasticity-inducing effects of fluoxetine (Winkel et al., 2020). We now demonstrate that the antidepressant fluoxetine induces disruption of interaction between TRKB and PTP $\sigma$, releasing TRKB from the suppressive activity of the phosphatase and promoting its activation (Fig. 4). These data suggest that reduced dephosphorylation of TRKB by PTP $\sigma$ is at least one mechanism through which antidepressant treatment promotes plasticity.

Antidepressants have recently been shown to directly interact with TRKB through its transmembrane domain (Casarotto et al.,
2021). Our data now show that the mutation that inhibits antidepressant binding to the transmembrane region of TRKB partially disrupts its interaction with $\mathrm{PTP} \sigma$, and that fluoxetine treatment has no further additive effect on TRKB:PTP $\sigma$ interaction in TRKB mutant cells. These data suggest that TRKB and PTP $\sigma$ interact in the transmembrane region of TRKB, and that binding of fluoxetine to TRKB disrupts TRKB:PTP $\sigma$ interaction.

Our findings suggest a general mechanism responsible for the opening of critical period-like plasticity in the adult brain by chABC and antidepressant treatment (Fig. 4). We propose that both methods converge on the same pathway involving reduced inhibitory interaction between TRKB and PTP $\sigma$ in $\mathrm{PV}^{+}$neurons, which releases TRKB from the PTP $\sigma$-mediated dephosphorylation and promotes its autophosphorylation. Chondroitinase treatment downregulates CSPG-mediated activation of $\mathrm{PTP} \sigma$, which allows for enhanced signaling of TRKB (Fig. 4). Antidepressants, on the other hand, disrupt the interaction between TRKB and PTP $\sigma$ in the membrane, promoting TRKB activation (Fig. 4).

Taken together, our data reveal that interaction between TRKB and PTP $\sigma$ in $\mathrm{PV}^{+}$interneurons is a critical regulator of chABC-induced and antidepressant-induced plasticity in the adult cortex. The similarity in the plasticity-promoting effects of chABC and antidepressants prompted us to focus on these two treatments, but there are a number of other methods known to reactivate juvenile-like plasticity in the adult cortex (Bavelier et al., 2010), such as enriched environment (Nithianantharajah and Hannan, 2006; Sale et al., 2007, 2014) and cross-modal manipulation of sensory functions (Rodríguez et al., 2018). It will be interesting in future studies to investigate whether induction of plasticity by these means recruits the same molecular pathways involving enhanced TRKB activation in $\mathrm{PV}^{+}$interneurons.

\section{References}

Antila H, Autio H, Turunen L, Harju K, Tammela P, Wennerberg K, YliKauhaluoma J, Huttunen HJ, Castrén E, Rantamäki T (2014) Utilization of in situ ELISA method for examining Trk receptor phosphorylation in cultured cells. J Neurosci Methods 222:142-146.

Autry AE, Monteggia LM (2012) Brain-derived neurotrophic factor and neuropsychiatric disorders. Pharmacol Rev 64:238-258.

Baho E, Chattopadhyaya B, Lavertu-Jolin M, Mazziotti R, Awad PN, Chehrazi P, Groleau M, Jahannault-Talignani C, Vaucher E, Ango F, Pizzorusso T, Baroncelli L, Di Cristo G (2019) p75 neurotrophin receptor activation regulates the timing of the maturation of cortical parvalbumin interneuron connectivity and promotes juvenile-like plasticity in adult visual cortex. J Neurosci 39:4489-4510.

Bavelier D, Levi DM, Li RW, Dan Y, Hensch TK (2010) Removing brakes on adult brain plasticity: from molecular to behavioral interventions. J Neurosci 30:14964-14971.

Berardi N, Pizzorusso T, Maffei L (2004) Extracellular matrix and visual cortical plasticity: freeing the synapse. Neuron 44:905-908.

Bradbury EJ, Moon LDF, Popat RJ, King VR, Bennett GS, Patel PN, Fawcett JW, McMahon SB (2002) Chondroitinase ABC promotes functional recovery after spinal cord injury. Nature 416:636-640.

Cang J, Kalatsky VA, Löwel S, Stryker MP (2005) Optical imaging of the intrinsic signal as a measure of cortical plasticity in the mouse. Vis Neurosci 22:685-691.

Cannarozzo C, Fred SM, Girych M, Biojone C, Enkavi G, Róg T, Vattulainen I, Casarotto PC, Castrén E (2020) Cholesterol recognition motifs in the transmembrane domain of the tyrosine kinase receptor family: the case for TRKB. bioRxiv 734012 .

Casarotto PC, Girych M, Fred SM, Kovaleva V, Moliner R, Enkavi G, Biojone C, Cannarozzo C, Sahu MP, Kaurinkoski K, Brunello CA, Steinzeig A, Winkel F, Patil S, Vestring S, Serchov T, Diniz CRAF, Laukkanen L, Cardon I, Antila H, Rog T, Piepponen TP, Bramham CR, Normann C, Lauri SE, Saarma M, Vattulainen I, Castrén E (2021) 
Antidepressant drugs act by directly binding to TRKB neurotrophin receptors. Cell, in press.

Castreń E (2013) Neuronal network plasticity and recovery from depression. JAMA Psychiatry 70:983-989.

Castrén E, Rantamäki T (2010) The role of BDNF and its receptors in depression and antidepressant drug action: reactivation of developmental plasticity. Dev Neurobiol 70:289-297.

Castrén E, Antila H (2017) Neuronal plasticity and neurotrophic factors in drug responses. Mol Psychiatry 22:1085-1095.

Coles CH, Shen Y, Tenney AP, Siebold C, Sutton GC, Lu W, Gallagher JT, Jones EY, Flanagan JG, Aricescu AR (2011) Proteoglycan-specific molecular switch for RPTP clustering and neuronal extension. Science 332:484-488.

Duan Y, Giger RJ (2010) A new role for RPTP $\sigma$ in spinal cord injury: signaling chondroitin sulfate proteoglycan inhibition. Sci Signal 3:pe6.

Duman RS, Monteggia LM (2006) A neurotrophic model for stress-related mood disorders. Biol Psychiatry 59:1116-1127.

Elchebly M, Wagner J, Kennedy TE, Lanctôt C, Michaliszyn E, Itié A, Drouin J, Tremblay ML (1999) Neuroendocrine dysplasia in mice lacking protein tyrosine phosphatase $\sigma$. Nat Genet 21:330-333.

Faux C, Hawadle M, Nixon J, Wallace A, Lee S, Murray S, Stoker A (2007) PTP $\sigma$ binds and dephosphorylates neurotrophin receptors and can suppress NGF-dependent neurite outgrowth from sensory neurons. Biochim Biophys Acta 1773:1689-1700.

Fawcett JW, Oohashi T, Pizzorusso T (2019) The roles of perineuronal nets and the perinodal extracellular matrix in neuronal function. Nat Rev Neurosci 20:451-465.

Fred SM, Laukkanen L, Brunello CA, Vesa L, Göös H, Cardon I, Moliner R, Maritzen T, Varjosalo M, Casarotto PC, Castrén E (2019) Pharmacologically diverse antidepressants facilitate TRKB receptor activation by disrupting its interaction with the endocytic adaptor complex AP-2. J Biol Chem 294:18150-18161.

Gogolla N, Caroni P, Lüthi A, Herry C (2009) Perineuronal nets protect fear memories from erasure. Science 325:1258-1261.

Haapasalo A, Koponen E, Hoppe E, Wong G, Castrén E (2001) Truncated trkB.T1 is dominant negative inhibitor of trkB.TK+-mediated cell survival. Biochem Biophys Res Commun 280:1352-1358.

Hensch TK (2005) Critical period plasticity in local cortical circuits. Nat Rev Neurosci 6:877-888.

Hippenmeyer S, Vrieseling E, Sigrist M, Portmann T, Laengle C, Ladle DR, Arber S (2005) A developmental switch in the response of DRG neurons to ETS transcription factor signaling. PLoS Biol 3:e159.

Hübener M, Bonhoeffer T (2014) Neuronal plasticity: beyond the critical period. Cell 159:727-737.

Hylin MJ, Orsi SA, Moore AN, Dash PK (2013) Disruption of the perineuronal net in the hippocampus or medial prefrontal cortex impairs fear conditioning. Learn Mem 20:267-273.

Karpova NN, Pickenhagen A, Lindholm J, Tiraboschi E, Kulesskaya N, Agústsdóttir A, Antila H, Popova D, Akamine Y, Bahi A, Sullivan R, Hen R, Drew LJ, Castrén E (2011) Fear erasure in mice requires synergy between antidepressant drugs and extinction training. Science 334:17311734.

Kurihara D, Yamashita T (2012) Chondroitin sulfate proteoglycans downregulate spine formation in cortical neurons by targeting tropomyosinrelated kinase B (TrkB) protein. J Biol Chem 287:13822-13828.

Kwok JCF, Dick G, Wang D, Fawcett JW (2011) Extracellular matrix and perineuronal nets in CNS repair. Dev Neurobiol 71:1073-1089.

Maya Vetencourt JF, Sale A, Viegi A, Baroncelli L, De Pasquale R, O'Leary OF, Castrén E, Maffei L (2008) The antidepressant fluoxetine restores plasticity in the adult visual cortex. Science 320:385-388.
Minichiello L, Korte M, Wolfer D, Kühn R, Unsicker K, Cestari V, RossiArnaud C, Lipp HP, Bonhoeffer T, Klein R (1999) Essential role for TrkB receptors in hippocampus-mediated learning. Neuron 24:401-414.

Nithianantharajah J, Hannan AJ (2006) Enriched environments, experiencedependent plasticity and disorders of the nervous system. Nat Rev Neurosci 7:697-709.

Pizzorusso T, Medini P, Berardi N, Chierzi S, Fawcett JW, Maffei L (2002) Reactivation of ocular dominance plasticity in the adult visual cortex. Science 298:1248-1251.

Rantamäki T, Hendolin P, Kankaanpää A, Mijatovic J, Piepponen P, Domenici E, Chao MV, Männistö PT, Castrén E (2007) Pharmacologically diverse antidepressants rapidly activate brain-derived neurotrophic factor receptor TrkB and induce phospholipase-Cgamma signaling pathways in mouse brain. Neuropsychopharmacology 32:2152-2162.

Rodriguez G, Chakraborty D, Schrode KM, Saha R, Uribe I, Lauer AM, Lee HK (2018) Cross-modal reinstatement of thalamocortical plasticity accelerates ocular dominance plasticity in adult mice. Cell Rep 24:3433-3440. e4.

Saarelainen T, Hendolin P, Lucas G, Koponen E, Sairanen M, MacDonald E, Agerman K, Haapasalo A, Nawa H, Aloyz R, Ernfors P, Castrén E (2003) Activation of the TrkB neurotrophin receptor is induced by antidepressant drugs and is required for antidepressant-induced behavioral effects. J Neurosci 23:349-357.

Sahu MP, Nikkilä O, Lågas S, Kolehmainen S, Castrén E (2019) Culturing primary neurons from rat hippocampus and cortex. Neuronal Signal 3: NS20180207.

Sale A, Maya Vetencourt JF, Medini P, Cenni MC, Baroncelli L, De Pasquale R, Maffei L (2007) Environmental enrichment in adulthood promotes amblyopia recovery through a reduction of intracortical inhibition. Nat Neurosci 10:679-681.

Sale A, Berardi N, Maffei L (2014) Environment and brain plasticity: towards an endogenous pharmacotherapy. Physiol Rev 94:189-234.

Shen Y, Tenney AP, Busch SA, Horn KP, Cuascut FX, Liu K, He Z, Silver J, Flanagan JG (2009) PTPsigma is a receptor for chondroitin sulfate proteoglycan, an inhibitor of neural regeneration. Science 326:592-596.

Shi W, Wei X, Wang X, Du S, Liu W, Song J, Wang Y (2019) Perineuronal nets protect long-term memory by limiting activity-dependent inhibition from parvalbumin interneurons. Proc Natl Acad Sci USA 116:2706327073.

Steinzeig A, Molotkov D, Castrén E (2017) Chronic imaging through "transparent skull" in mice. PLoS One 12:e0181788.

Takahashi H, Arstikaitis P, Prasad T, Bartlett TE, Wang YT, Murphy TH, Craig AM (2011) Postsynaptic TrkC and presynaptic PTP $\sigma$ function as a bidirectional excitatory synaptic organizing complex. Neuron 69:287303.

Umemori J, Winkel F, Didio G, Llach Pou M, Castrén E (2018) iPlasticity: induced juvenile-like plasticity in the adult brain as a mechanism of antidepressants. Psychiatry Clin Neurosci 72:633-653.

Wang D, Fawcett J (2012) The perineuronal net and the control of CNS plasticity. Cell Tissue Res 349:147-160.

Wiesel TN (1982) Postnatal development of the visual cortex and the influence of environment. Nature 299:583-591.

Winkel F, Voigt MB, Didio G, Mateo S, Jetsonen EL, Pou M, Steinzeig A, Ryazantseva M, Harkki J, Englund J, Khirug S, Rivera C, Palva S, Taira T, Lauri S, Umemori J, Castren E (2020) TrkB activation in Parvalbumin interneurons orchestrates cortical plasticity. bioRxiv. doi: 10.1101/2020. 04.27.063503

Zheng J, Shen WH, Lu TJ, Zhou Y, Chen Q, Wang Z, Xiang T, Zhu YC, Zhang C, Duan S, Xiong ZQ (2008) Clathrin-dependent endocytosis is required for TrkB-dependent Akt-mediated neuronal protection and dendritic growth. J Biol Chem 283:13280-13288. 